\title{
Sulfur dioxide oxidation induced mechanistic branching and particle formation during the ozonolysis of $\beta$-pinene and 2-butene $\dagger$
}

\author{
Thomas Zeuch* \\ Received 28th August 2012, Accepted 18th September 2012 \\ DOI: $10.1039 / \mathrm{c} 2 \mathrm{cp} 42992 \mathrm{f}$
}

Philip T. M. Carlsson, Claudia Keunecke, Bastian C. Krüger, Mona-C. Maaß and

Recent studies have suggested that the reaction of stabilised Criegee Intermediates (CIs) with sulfur dioxide $\left(\mathrm{SO}_{2}\right)$, leading to the formation of a carbonyl compound and sulfur trioxide, is a relevant atmospheric source of sulfuric acid. Here, the significance of this pathway has been examined by studying the formation of gas phase products and aerosol during the ozonolysis of $\beta$-pinene and 2-butene in the presence of $\mathrm{SO}_{2}$ in the pressure range of 10 to 1000 mbar. For $\beta$-pinene at atmospheric pressure, the addition of $\mathrm{SO}_{2}$ suppresses the formation of the secondary ozonide and leads to highly increased nopinone yields. A complete consumption of $\mathrm{SO}_{2}$ is observed at initial $\mathrm{SO}_{2}$ concentrations below the yield of stabilised CIs. In experiments using 2-butene a significant consumption of $\mathrm{SO}_{2}$ and additional formation of acetaldehyde are observed at 1 bar. A consistent kinetic simulation of the experimental findings is possible when a fast $\mathrm{CI}+\mathrm{SO}_{2}$ reaction rate in the range of recent direct measurements [Welz et al., Science, 2012, 335, 204] is used. For 2-butene the addition of $\mathrm{SO}_{2}$ drastically increases the observed aerosol yields at higher pressures. Below 60 mbar the $\mathrm{SO}_{2}$ oxidation induced particle formation becomes inefficient pointing to the critical role of collisional stabilisation for sulfuric acid controlled nucleation at low pressures.

The atmospheric abundance of sulfuric acid $\left(\mathrm{H}_{2} \mathrm{SO}_{4}\right)$ is closely related to observations of new particle formation. ${ }^{1}$ The dominant $\mathrm{H}_{2} \mathrm{SO}_{4}$ forming pathway of atmospheric relevance is assumed to start with the oxidation of sulfur dioxide $\left(\mathrm{SO}_{2}\right)$ to sulfur trioxide $\left(\mathrm{SO}_{3}\right)$ by the $\mathrm{OH}$ radical. ${ }^{2}$ Low-volatility organic compounds are believed to contribute to the subsequent growth of the clusters to nanoparticles. ${ }^{3}$ Such highly oxidized species are formed in the atmospheric degradation of many hydrocarbons from biogenic and anthropogenic sources by $\mathrm{OH}, \mathrm{NO}_{3}$ and ozone.

The importance of cross reactions between organic chemistry and sulfur chemistry for aerosol formation during alkene ozonolysis is known for a long time. ${ }^{4-8}$ Hatakeyama et al. analysed the particle formation during the ozonolysis of 2-butene and other alkenes in the presence of $\mathrm{SO}_{2}{ }^{6}$ An intriguing result of this early work was the reduction of sulfuric acid yields in aerosol

Institut für Physikalische Chemie, Universität Göttingen, Tammannstr. 6,37077Göttingen, Germany.E-mail: tzeuch1@gwdg.de

$\dagger$ Electronic supplementary information (ESI) available. See DOI: $10.1039 / \mathrm{c} 2 \mathrm{cp} 42992 \mathrm{f}$ samples from trans-2-butene with decreasing pressure, reaching zero at the lowest pressures. The authors concluded that $\mathrm{SO}_{2}$ is oxidized by stabilised Criegee Intermediates (CIs). 20 years later Berndt et al. concluded for the ozonolysis of 2-butene (as well as $\alpha$-pinene and tetramethylethylene) in the presence of $\mathrm{SO}_{2}$ that the oxidation of $\mathrm{SO}_{2}$ by $\mathrm{OH}$ is the dominant pathway for $\mathrm{H}_{2} \mathrm{SO}_{4}$ formation but at the same time reported significant contributions from $\mathrm{CI}+\mathrm{SO}_{2}$. We note that Berndt et al. used much lower reactant concentrations being close to atmospheric conditions. For cyclohexene $+\mathrm{O}_{3}$ we found in previous work a relation of generated particle number densities and $\mathrm{SO}_{2}$ concentrations, which were at low $\mathrm{H}_{2} \mathrm{SO}_{4} / \mathrm{SO}_{2}$ concentrations consistent with $\mathrm{SO}_{2}+\mathrm{OH}$ being the only source of sulfuric acid. ${ }^{9}$

In a recent paper the first direct kinetic measurements of the reaction of the $\mathrm{Cl}-\mathrm{CI}\left(\mathrm{CH}_{2} \mathrm{OO}\right)$ with $\mathrm{SO}_{2}$ were reported employing single photon, near threshold ionization for specific CI detection. ${ }^{10}$ The measured rate coefficient was significantly faster than previously believed $\left(3.9 \times 10^{-11} \mathrm{~cm}^{3} \mathrm{~s}^{-1}\right.$ compared to 0.04 to $8 \times 10^{-13} \mathrm{~cm}^{3} \mathrm{~s}^{-1}$, see discussion in ref. 10), providing experimental evidence for theoretical work of Kurtén et al. on the oxidation of $\mathrm{SO}_{2}$ to $\mathrm{SO}_{3}$ by gas-phase organic oxidants. ${ }^{11}$ These results suggested that $\mathrm{CI}+\mathrm{SO}_{2}$ may contribute significantly to atmospheric $\mathrm{H}_{2} \mathrm{SO}_{4}$ production. This interpretation is bolstered by a current combined field and laboratory study. ${ }^{12}$ However, due to the experimental approach the direct kinetic measurements were performed at 4 Torr and have not been extended to substituted CIs at atmospheric pressure. ${ }^{13}$ The aim of the present study is to bridge this gap by studying the $\mathrm{CI}+\mathrm{SO}_{2}$ reaction in the context of pressure dependent mechanistic branching and aerosol formation during alkene ozonolysis. The alkenes under study are $\beta$-pinene and 2-butene (mixture of cis and trans), which produce predominantly ${ }^{14}$ or solely substituted CIs in the reactions with ozone.

Direct kinetic measurements are highly desirable but unfortunately limited by the availability of suitable precursors for the photodissociation induced specific preparation of larger CIs. Therefore we make use of the growing network of interdependencies for ozonolysis reactions. ${ }^{14-16}$ In the case of $\beta$-pinene, a recent extensive theoretical study provided crucial kinetic information which is needed for robust modelling of the first reaction steps. ${ }^{14}$ For the ozonolysis of 2-butene the results of absolute rate coefficient determinations of reactions involving the $\mathrm{C} 2-\mathrm{CI}\left(\mathrm{CH}_{3} \mathrm{CHOO}\right)$ are available. ${ }^{17}$ 
All ozonolysis experiments were performed in our static variable pressure reaction chamber with a volume of $64 \mathrm{~L}$ and two premixing chambers of $40 \mathrm{~L}$ volume. One of them is used as an ozone reservoir and is equipped with UV optics for a continuous measurement of $\mathrm{O}_{3}$ concentrations. Concentrations of reactants and the product yields were determined using infra-red spectroscopy (Bruker IFS 66, $12 \mathrm{~m}$ path length in the cell). $\mathrm{SO}_{2}$ concentrations were determined by means of IR spectroscopy and volumetry as described in detail in a recent paper. ${ }^{9}$ A particle classifier (TSI SMPS 3936 with NDMA (3085) and LDMA (3081) as well as a 3022 CPC (condensation particle counter)) was used for particle measurements (operation parameters: 2 litres per minute (lpm) sheath flow and $0.2 \mathrm{lpm}$ sample flow). The pressure variation was achieved by expanding the reactants from the premixing chambers into the evacuated reaction cell within $3 \mathrm{~s}$. For starting pressures between 25 and $1000 \mathrm{mbar}$ this procedure results in final pressures between 10 and 450 mbar. For experiments at higher pressures additional synthetic air is filled in the reaction cell directly after the expansion (approx. $15 \mathrm{~s}$ filling time). The fast reactant mixing allows the use of relatively high initial concentrations which effectively suppress the heterogeneous loss of reactants and products to the wall. Further details on the apparatus and the applied procedures are given in recent papers. ${ }^{9,16}$ All chemicals used were of commercial grade (see $\operatorname{ESI} \dagger$ ).

First, we discuss the results for the ozonolysis of $\beta$-pinene. This terpene is of atmospheric relevance and many experimental and theoretical studies have been published on this reaction (ref. 14, 16, 18-22 and references therein) with the focus on both stable gas phase product formation and the production of SOA. The extensive theoretical study of Nguyen et al. revealed that two distinct, non-interconvertible conformers of $\mathrm{C} 9-\mathrm{CI}(-\mathrm{COO}$ function either points to or away from internal ring, see ref. 14) are formed. Only $5 \% \mathrm{CH}_{2} \mathrm{OO}$ yield was predicted. These properties of $\beta$-pinene ozonolysis indicate that this is a suitable system for studying mechanistic features related to the reactions of larger substituted, biogenic CIs with $\mathrm{SO}_{2}$. The key observations for such experiments are illustrated in the upper panels of Fig. 1. Addition of $3 \mathrm{ppm} \mathrm{SO}_{2}$ to an initial mixture of $9 \mathrm{ppm} \mathrm{O}_{3}$ and $30 \mathrm{ppm} \beta$-pinene has two significant effects on the IR final product spectrum: the additional formation of a carbonyl compound and the reduced formation of a product with a characteristic double peak near $1100 \mathrm{~cm}^{-1}$ (features A and B in the IR difference spectrum, upper panel of Fig. 1). Feature B was previously assigned to a secondary ozonide (SOZ). ${ }^{16,19}$ The carbonyl compound is most likely nopinone, which is deduced from the fit of the $\mathrm{C}=\mathrm{O}$ stretch band and other characteristic nopinone features when compared to a pure product spectrum (see Fig. S1 in the ESI $\dagger$ ). In addition, we observe a complete consumption of $\mathrm{SO}_{2}$ at 1 bar (see the lower trace in the left middle panel of Fig. 1). At $10 \mathrm{ppm}$ initial concentration unreacted $\mathrm{SO}_{2}$ is observed in the end product spectrum. At this initial $\mathrm{SO}_{2}$ concentration the characteristic $\mathrm{SOZ}$ features are completely suppressed (see the right middle panel of Fig. 1). All these findings can be explained by the direct oxidation of $\mathrm{SO}_{2}$ to $\mathrm{SO}_{3}$ via the fast reaction with a stabilised $\mathrm{CI}^{7,10,11}$ If $\mathrm{SO}_{2}$ is predominantly consumed via $\mathrm{CI}+\mathrm{SO}_{2}$ the picture will change at low pressure where a much lower fraction of CIs is stabilised enough to take part in bimolecular reactions. ${ }^{14}$ The upper trace
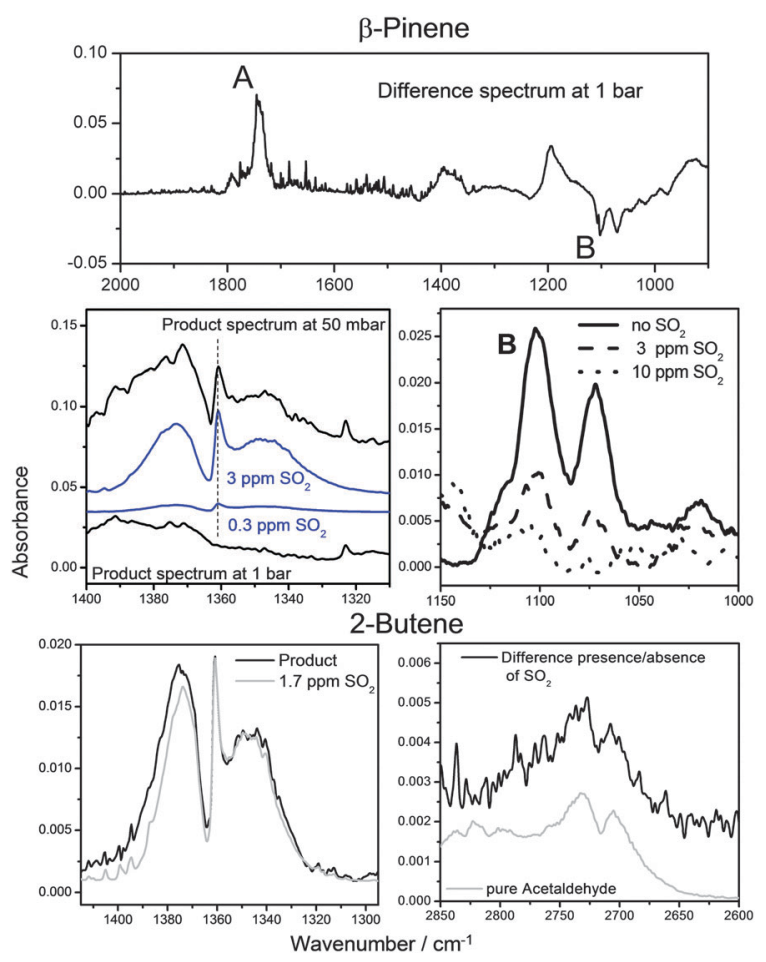

Fig. 1 IR spectra of final products from $\beta$-pinene (upper and middle panels) and 2-butene (lower panels) ozonolysis at initial concentrations of $30 \pm 2 \mathrm{ppm}$ alkene and $9 \pm 0.5 \mathrm{ppm}$ ozone at $295 \pm 0.5 \mathrm{~K}$. Upper panel: difference product spectrum presence-absence of 3 ppm $\mathrm{SO}_{2}$. Middle panels: (left) complete (lower trace, 1 bar) and minor (upper trace, 50 mbar) consumption of $\mathrm{SO}_{2}$ at $3 \mathrm{ppm}$ initial concentration; middle traces show spectra of 0.3 and $3 \mathrm{ppm} \mathrm{SO}_{2}$ for comparison. (right) Suppression of the characteristic band of the secondary ozonide upon $\mathrm{SO}_{2}$ addition. Lower panels: (left) partial consumption of $\mathrm{SO}_{2}$ at $3 \pm 0.2 \mathrm{ppm}$ initial concentration. (right) Additional acetaldehyde formation upon $\mathrm{SO}_{2}$ addition in the difference IR product spectrum (presence-absence of $3 \pm 0.2 \mathrm{ppm} \mathrm{SO}_{2}$ ).

in the left middle panel of Fig. 1 belongs to an experiment conducted at 50 mbar with an initial $\mathrm{SO}_{2}$ concentration of $3 \mathrm{ppm}$. The comparison with the pure substance spectrum of the same amount of $\mathrm{SO}_{2}$ indicates that only a minor fraction is consumed. This finding strongly supports the interpretation that $\mathrm{CI}+\mathrm{SO}_{2}$ is the dominant pathway for $\mathrm{SO}_{2}$ consumption at 1 bar. Similar results were obtained for the 2-butene $+\mathrm{O}_{3}$ reaction. In the lower panels of Fig. 1 the key results of these experiments are illustrated. At an initial concentration of $3 \pm$ $0.2 \mathrm{ppm} \mathrm{\textrm {SO } _ { 2 }}$ a consumption of $1.3 \pm 0.2 \mathrm{ppm} \mathrm{SO}_{2}$ (lower left panel of Fig. 1) and additional formation of acetaldehyde are observed (lower right panel of Fig. 1). The less efficient consumption of $\mathrm{SO}_{2}$ is consistent with a lower fraction of stabilised CIs for 2-butene ozonolysis (see e.g. ref. 6 and 17 and discussion therein). This finding suggests that the fast $\mathrm{CI}+\mathrm{SO}_{2}$ reaction can give direct access to stabilised CI yields on the basis of a titration with $\mathrm{SO}_{2}$. To bolster this conclusion we performed similar experiments using ethylene at 1 bar and initial concentrations of $100 \pm 5 \mathrm{ppm}_{2} \mathrm{H}_{4}, 8.5 \pm 0.5 \mathrm{ppm}$ $\mathrm{O}_{3}$ and $6 \pm 0.3 \mathrm{ppm} \mathrm{SO}_{2}$ (see Fig. S2 in ESI $\dagger$ ). The observed consumption of $4.2 \pm 0.3 \mathrm{ppm} \mathrm{SO}_{2}$ indicates an yield of $50 \pm 15 \%$ of stabilised CIs in agreement with the extensive study of Horie and Moortgat ${ }^{23}$ but larger than other 
reports (see Hasson et al. $^{24}$ ). An in-depth analysis of this interesting effect should include the isomer distinction of 2-butene, a rigorous calibration of the additional carbonyl compound formation as a function of pressure and - where possible - relative to adduct formation. ${ }^{7}$ This is beyond the scope of this communication and will be addressed in a subsequent full length paper. Several test experiments were performed for all alkenes using cyclohexane as an $\mathrm{OH}$ scavenger. No measurable effect on the $\mathrm{SO}_{2}$ consumption was observed.

In the next section the experimental results are compared to predicted product yields derived by kinetic modelling of the ozonolysis reaction. To this end the mechanism applied in the preceding work ${ }^{9}$ has been adopted to the alkenes under study using kinetic data provided by Nguyen et al. ${ }^{14}$ for $\beta$-pinene and Fenske et al. for 2-butene. ${ }^{17}$ We have now included the $\mathrm{CI}+\mathrm{SO}_{2}$ reaction which was not considered for cyclohexene + $\mathrm{O}_{3}$ due to the absence of stabilised CIs. ${ }^{15}$ Further details on the kinetic modeling are given in the ESI. $\dagger$

We simulated the ozonolysis of $\beta$-pinene for the conditions given in the caption of Fig. 1 with an initial amount of $3 \mathrm{ppm}$ $\mathrm{SO}_{2}$ using different rate coefficients for the $\mathrm{CI}+\mathrm{SO}_{2}$ reaction. A complete consumption of $\mathrm{SO}_{2}$ as observed in the experiment is only predicted when a value larger than $1 \times 10^{-11} \mathrm{~cm}^{3} \mathrm{~s}^{-1}$ is applied (see Fig. 2). Use of a rate coefficient of $1 \times 10^{-11} \mathrm{~cm}^{3} \mathrm{~s}^{-1}$ would according to the simulation result in a final $\mathrm{SO}_{2}$ concentration of $0.3 \mathrm{ppm}$, which is not observed in the experiment (see the left middle panel of Fig. 1). Similar results were obtained for 2-butene $+\mathrm{O}_{3}$ and the partial consumption of $\mathrm{SO}_{2}$ (see Fig. S3 in the ESI $\dagger$ ). Also for this alkene the best agreement between experimental findings and model predictions is found when a high value for $k\left(\mathrm{CI}+\mathrm{SO}_{2}\right)$, larger than $1 \times 10^{-11} \mathrm{~cm}^{3} \mathrm{~s}^{-1}$, is used. These findings suggest that the direct measurements of Welz et al. for $k\left(\mathrm{CI}+\mathrm{SO}_{2}\right)$ at 4 Torr give a suitable estimate for larger CIs at higher pressure. However, we note here that the modelling results depend to some degree on the yields of stabilised CIs. If the added amount of $\mathrm{SO}_{2}$ exceeds the applied fraction of stabilised CIs the simulation predicts that $\mathrm{SO}_{2}$ is not completely consumed for simple stoichiometric reasons. This implies an intrinsic uncertainty of model predictions regarding the final $\mathrm{SO}_{2}$ concentrations. We further note that the conditions of our experiment (relatively high initial reactant concentrations) favor bimolecular chemistry over the consumption of CIs by unimolecular reactions. Assuming unimolecular rates in the range of 1 to $100 \mathrm{~s}^{-1}$ would only slightly change the predicted consumption of $\mathrm{SO}_{2}$ in case of $\beta$-pinene, for 2-butene

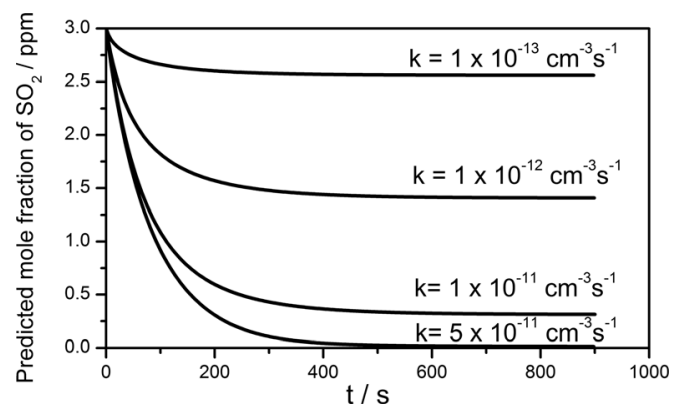

Fig. 2 Simulated mole fraction profiles of $\mathrm{SO}_{2}$ for an initial mixture of $30 \mathrm{ppm} \beta$-pinene and $9 \mathrm{ppm}$ ozone at $298 \mathrm{~K}$ and 1 bar using different rate coefficients for $\mathrm{CI}+\mathrm{SO}_{2}$. the influence would be larger. However, Nguyen et al. ${ }^{14}$ found a consistency of their predicted and experimentally determined ${ }^{17}$ isomerisation rates of thermalised CIs for the two alkenes under study. In the light of these considerations we hesitate to use a simple best fit of $k\left(\mathrm{CI}+\mathrm{SO}_{2}\right)$ to match the point where the final $\mathrm{SO}_{2}$ concentration is below the detection limit to pinpoint the rate coefficient. Nonetheless, the combined results of experiments and kinetic modelling suggest that $k(\mathrm{CI}+$ $\mathrm{SO}_{2}$ ) is likely above $1 \times 10^{-11} \mathrm{~cm}^{3} \mathrm{~s}^{-1}$ and clearly above $3 \times 10^{-12} \mathrm{~cm}^{3} \mathrm{~s}^{-1}$ for both alkenes under study. Independent evidence for this lower limit in the case of $\beta$-pinene comes from the observed suppression of SOZ formation (see Fig. 1 and Fig. S4 in the ESI $\dagger$ ) where the relative rate of CI + carbonyl and $\mathrm{CI}+\mathrm{SO}_{2}$ is probed. The effective suppression shows that the latter reaction is much faster. However, we have to state that the evidence from kinetic modelling is limited in case fast, yet unexplored $\mathrm{SO}_{2}$ consuming reactions exist. Furthermore, alkene specific rates have to be considered (see ref. 12 for results on $\alpha$-pinene and limonene). A critical point for both kinetic modelling and experimental studies is the unimolecular rate coefficients of isomerisation reactions of stabilised CIs. Assuming in the kinetic simulation significantly lower unimolecular reaction rates than reported by Fenske et al. ${ }^{17}$ would in case of 2-butene allow a consistency with a lower range of values for $k\left(\mathrm{CI}+\mathrm{SO}_{2}\right)$. We note that measurements at low initial reactant concentrations, which employ the detection of the product $\mathrm{H}_{2} \mathrm{SO}_{4}$, are more closely linked to unimolecular CI chemistry. Here, the rate coefficient $k\left(\mathrm{CI}+\mathrm{SO}_{2}\right)$ is measured relative to the CI loss rate. Another important point is that measuring $\mathrm{H}_{2} \mathrm{SO}_{4}$ formation instead of $\mathrm{CI}$ or $\mathrm{SO}_{2}$ consumption would lead to lower $k\left(\mathrm{CI}+\mathrm{SO}_{2}\right)$ values when $\mathrm{CI}-\mathrm{SO}_{2}$ adducts are stabilised to a significant degree (see also discussions in ref. 12, 14 and 26).

In the following the key results on aerosol yields as a function of $\mathrm{SO}_{2}$ addition will be discussed. All experiments were performed at 450 mbar to achieve a high reproducibility by fast reactant mixing. ${ }^{9}$ For 2-butene the observed $\mathrm{SO}_{2}$ consumption and acetaldehyde formation suggest an effective production of $\mathrm{H}_{2} \mathrm{SO}_{4}$. The kinetic model predicts $\mathrm{H}_{2} \mathrm{SO}_{4}$ formation via $\mathrm{CI}+\mathrm{SO}_{2}$ to be at least two orders of magnitude faster than via $\mathrm{OH}+\mathrm{SO}_{2}$. This should manifest itself in a large influence of $\mathrm{SO}_{2}$ addition on the observed aerosol formation. In the left panel of Fig. 3 particle numbers from

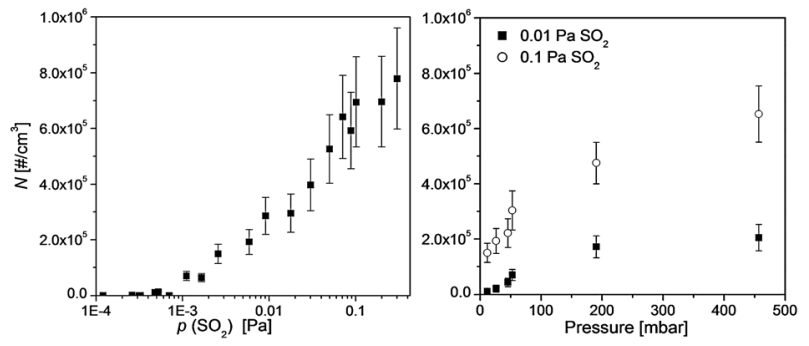

Fig. 3 Left panel: particle numbers as a function of added $\mathrm{SO}_{2}$ concentrations for the ozonolysis of 2-butene (1 $\mathrm{Pa}$ 2-butene, $0.1 \mathrm{~Pa} \mathrm{O}_{3}$ ) at 450 mbar. Right panel: pressure dependence of particle numbers upon addition of $0.01 \mathrm{~Pa} \mathrm{SO}_{2}$ and $0.1 \mathrm{~Pa} \mathrm{SO}_{2}$. Error bars $(95 \%$ confidence interval) were derived exemplarily from experiments under fixed conditions. 
2-butene ozonolysis (1 ppm ozone, $10 \mathrm{ppm}$ 2-butene) as a function of the added amount of $\mathrm{SO}_{2}$ are shown. In the absence of $\mathrm{SO}_{2}$ no particle formation is observed, above $0.0004 \mathrm{~Pa}$ (4 ppb at 1 bar) $\mathrm{SO}_{2}$ aerosol formation starts and is highly intensified when the fraction of $\mathrm{SO}_{2}$ in the mixture is further increased. This finding suggests that $\mathrm{SO}_{2}$ oxidation by CIs provides an efficient and kinetically controllable gas phase source of sulfuric acid, which can be used to study $\mathrm{H}_{2} \mathrm{SO}_{4}$ induced nucleation dynamics in laboratory experiments. When reducing the pressure a slight decrease in particle numbers between 450 and $60 \mathrm{mbar}$ is found. This effect can be related to the pressure dependence of stabilised CI yields (see results for the related alkenes, ethylene and tetramethylethylene ${ }^{15,25}$ ). Below 60 mbar, however, the particle formation is significantly reduced which is a similar finding to our previous work on $\mathrm{SO}_{2}$ oxidation induced aerosol formation during cyclohexene ozonolysis, pointing to the critical role of collisional stabilisation for $\mathrm{H}_{2} \mathrm{SO}_{4}$ induced particle formation. ${ }^{9}$ The effect on observed particle numbers upon adding $\mathrm{SO}_{2}$ during $\beta$-pinene ozonolysis is much weaker because particles are effectively formed in the absence of $\mathrm{SO}_{2}$ (see Fig. S5 in the ESI $\dagger$ ). ${ }^{16}$ Different from $\alpha$-pinene ozonolysis ${ }^{9}$ we find additional aerosol mass build up below 100 mbar for $\beta$-pinene which again can be explained by the much higher abundance of stabilised CIs in the case of $\beta$-pinene at low pressure. ${ }^{14,15}$

In summary, we have characterized several effects of $\mathrm{SO}_{2}$ addition on final gas phase product and aerosol formation during the ozonolysis of $\beta$-pinene and 2-butene. The experimental findings, namely the efficient $\mathrm{SO}_{2}$ consumption, additional carbonyl and suppressed SOZ formation in combination with the kinetic modelling result in a consistent picture when a fast reaction of stabilised CIs with $\mathrm{SO}_{2}$ at ambient pressure is assumed. Thus the direct kinetic results of Welz et al. on the $\mathrm{CH}_{2} \mathrm{OO}+\mathrm{SO}_{2}$ reaction at low pressure ${ }^{10}$ seemingly provide a reliable estimate for larger, substituted CIs at tropospheric pressure. At the same time we have to be aware that uncertainties concerning the unimolecular reaction rates of stabilised CIs and an incomplete understanding of $\mathrm{H}_{2} \mathrm{SO}_{4}$ formation pathways may imply systematic errors which cause discrepancies between different experimental approaches. ${ }^{10,12,14,17,26}$ Therefore additional direct measurements of $\mathrm{CI}+\mathrm{SO}_{2}$ reactions rates are desirable. The observed effects on particle formation under $\mathrm{SO}_{2}$ addition give additional experimental evidence for both the important role of the $\mathrm{CI}+\mathrm{SO}_{2}$ reaction in atmospheric aerosol formation ${ }^{12}$ and the inefficiency of sulfuric acid based nucleation at low pressures. ${ }^{9}$

\section{Acknowledgements}

The continuous support for this work by Prof. Martin Suhm and Prof. Karlheinz Hoyermann is gratefully acknowledged. We thank the DFG (GRK 782) for funding.

\section{References}

1 M. Kulmala, Science, 2003, 302, 1000-1001.

2 M. Sipilä, T. Berndt, T. Petäjä, D. Brus, J. Vanhanen, F. Stratmann, J. Patokoski, R. L. Mauldin, A.-P. Hyvärinen, H. Lihavainen and M. Kulmala, Science, 2010, 327, 1243-1246.

3 N. M. Donahue, E. R. Trump, J. R. Pierce and I. Riipinen, Geophys. Res. Lett., 2011, 38, L16801.

4 R. A. Cox and S. A. Penkett, Nature, 1971, 230, 321-322.

5 H. R. Schulten and U. Schurath, J. Phys. Chem., 1975, 79, 51-57.

6 S. Hatakeyama, H. Kobayashi and H. Akimoto, J. Phys. Chem., 1984, 88, 4736-4739.

7 S. Hatakeyama and H. Akimoto, Res. Chem. Intermed., 1994, 20, 503-524.

8 T. Berndt, O. Böge and F. Stratmann, Atmos. Environ., 2004, 38, 2145-2153.

9 P. T. M. Carlsson, J. E. Dege, C. Keunecke, B. C. Krüger, J. L. Wolf and T. Zeuch, Phys. Chem. Chem. Phys., 2012, 14, 11695-11705.

10 O. Welz, J. D. Savee, D. L. Osborn, S. S. Vasu, C. J. Parcival, D. E. Shallcross and C. A. Taatjes, Science, 2012, 335, 204-207.

11 T. Kurtén, J. R. Lane, S. Jørgensen and H. G. Kjaergaard, J. Phys. Chem. A, 2011, 302, 8669-8681.

12 R. L. Mauldin III, T. Berndt, M. Sipilä, P. Paasonen, T. Petäjä, S. Kim, T. Kurtén, F. Stratmann, V.-M. Kerminen and M. Kulmala, Nature, 2012, 488, 193-196.

13 G. Marston, Science, 2012, 335, 178-179.

14 T. L. Nguyen, J. Peeters and L. Vereecken, Phys. Chem. Chem. Phys., 2009, 11, 5643-5656.

15 N. M. Donahue, G. T. Drozd, S. A. Epstein, A. A. Presto and J. H. Kroll, Phys. Chem. Chem. Phys., 2011, 13, 10848-10857.

16 J. L. Wolf, S. Richters, J. Pecher and T. Zeuch, Phys. Chem. Chem. Phys., 2011, 13, 10952-10964.

17 J. D. Fenske, A. S. Hasson, A. Ho and S. E. Paulson, J. Phys. Chem. A, 2000, 104, 9921-9932.

18 K. Griesbaum, V. Miclaus and I. C. Jung, Environ. Sci. Technol., 1998, 32, 647-649.

19 R. Winterhalter, P. Neeb, D. Grossmann, A. Kolloff, O. Horie and G. K. Moortgat, J. Atmos. Chem., 2000, 35, 165-197.

20 M. Jaoui and R. M. Kamens, J. Atmos. Chem., 2003, 43, 101-141.

21 J. B. Burkholder, T. Baynard, A. R. Ravishankara and E. R. Lovejoy, J. Geophys. Res., [Atmos.], 2007, 112, D10216.

22 Y. Ma and G. Marston, Phys. Chem. Chem. Phys., 2008, 10, 6115-6126.

23 O. Horie and G. K. Moortgat, Atmos. Environ, 1991, 25, 1881-1896.

24 A. S. Hasson, G. Orzechowska and S. E. Paulson, J. Geophys. Res., [Atmos.], 2001, 106, 34131-34142.

25 M. Olzmann, E. Kraka, D. Cremer, R. Gutbrod and S. Andersson, J. Phys. Chem. A, 1997, 101, 9421-9429.

26 T. Berndt, T. Jokinen, R. L. Mauldin, III, T. Petäjä, H. Herrmann, H. Junninen, P. Paasonen, D. R. Worsnop and M. Sipilä, J. Phys. Chem. Lett., 2012, 3, 2892-2896. 